sion as to the presence or absence of sand and earthy material in a drug sample. ${ }^{10}$ The determination of the amount of acid-insoluble ash present in a drug will therefore be valuable as a test for purity. It requires very little more time than the ash determinations, and is, as we have seen, sometimes of even more value than the latter in the final judgment of cleanliness. The addition of an acid-insoluble ash standard will permit the raising of the total ash standard of a number of drugs, such as rhubarb, mentioned above, in order to cover wide variations due, probably, in the main, to soil conditions, and at the same time guard against careless handling or gross adulteration of drugs both in the whole and particularly in the powdered form.

The following simple method has been followed by the writers for a number of years: ${ }^{11}$

To the ash obtained by the U. S. Pharmacopoeia method is added $25 \mathrm{Cc}$. of Io percent hydrochloric acid. This is digested on a steam bath for about io minutes, filtered, washed, ignited over a bunsen burner, cooled, and weighed.

While it is well known that a certain amount of siliceous matter can only be rendered insoluble in hydrochloric acid by several evaporations to dryness, the method as given approximates that given for the determination of ash insoluble in acid in the Bureau of Chemistry Bulletin I07, Revised (1912), page 162, under "Methods for the Analysis of Spices," and is sufficiently accurate for purposes of crude drug control.

Pharmacognosy Laboratory, BURFAU OF CHEMISTRY

U. S. Department OE Agriculture.

\title{
ON THE SHRINKAGE OF ALCOHOL-WATER MIXTURES.
}

\author{
BY HORATIO C. WOOD, JR., M.D.
}

The United States Pharmacopoeia states that when 500 mils of alcohol are mixed with 500 mils of water "if the two liquids are measured at the temperature of $25^{\circ}$ $\mathrm{C}$, the mixture when cooled to the same temperature will measure about 970 mils." In some experiments which I have been engaged in, it was important to know what volume percentage of alcohol would result from mixing alcohol of a given strength with water. It is evident that a mixture, for example, of equal volumes of ab solute

${ }^{10}$ Fortunately the dust, dirt, and sand often adhering to drugs after collection can, to a considerable degree, be removed, even if the drugs are in the dried condition. Rogers and Newcomb (loc. cit.) have shown this in the case of digitalis, and we also have had similar experience with other drugs (mustard, for example). The importance and feasibility of cleaning drugs, however, appears to be not so widely recognized as it should be. The more the machines and methods used in the grain and related industries are applied to the cleaning of drugs and spices, the less difficulty will the trade experience in obtaining high grade products.

11 To demonstrate the presence of sand and dirt directly in a powdered drug, without an ash analysis or microscopic examination, we have in a few instances floated the material on carbon tetrachloride, a liquid of high specific gravity (1.630). The vegetable matter usually floated on the surface, while the mineral impurities sank to the bottom. A very dirty commercial sample of Pennyroyal leaves so treated yielded a precipitate which, when dried, amounted to 26.7 percent while an acid-insoluble ash determination gave 27.9 percent, the two results being in surprisingly close agreement. 
alcohol and water, would give a solution containing more than 50 percent by volume of alcohol, because while the amount of alcohol remains the same there is a shrinkage in the total volume of approximately 3 percent. It is manifest that the statement of the Pharmacopoeia is too indefinite to be of any scientific use; moreover, it is important to know whether the shrinkage is at the same rate for all proportions; that is, would a mixture of one part of alcohol with two parts of water diminish in volume in the same proportion, as a mixture of equal parts? As I have been unable to find this data, I have made a small series of observations to determine what the degree of shrinkage is with various proportions of alcohol and water.

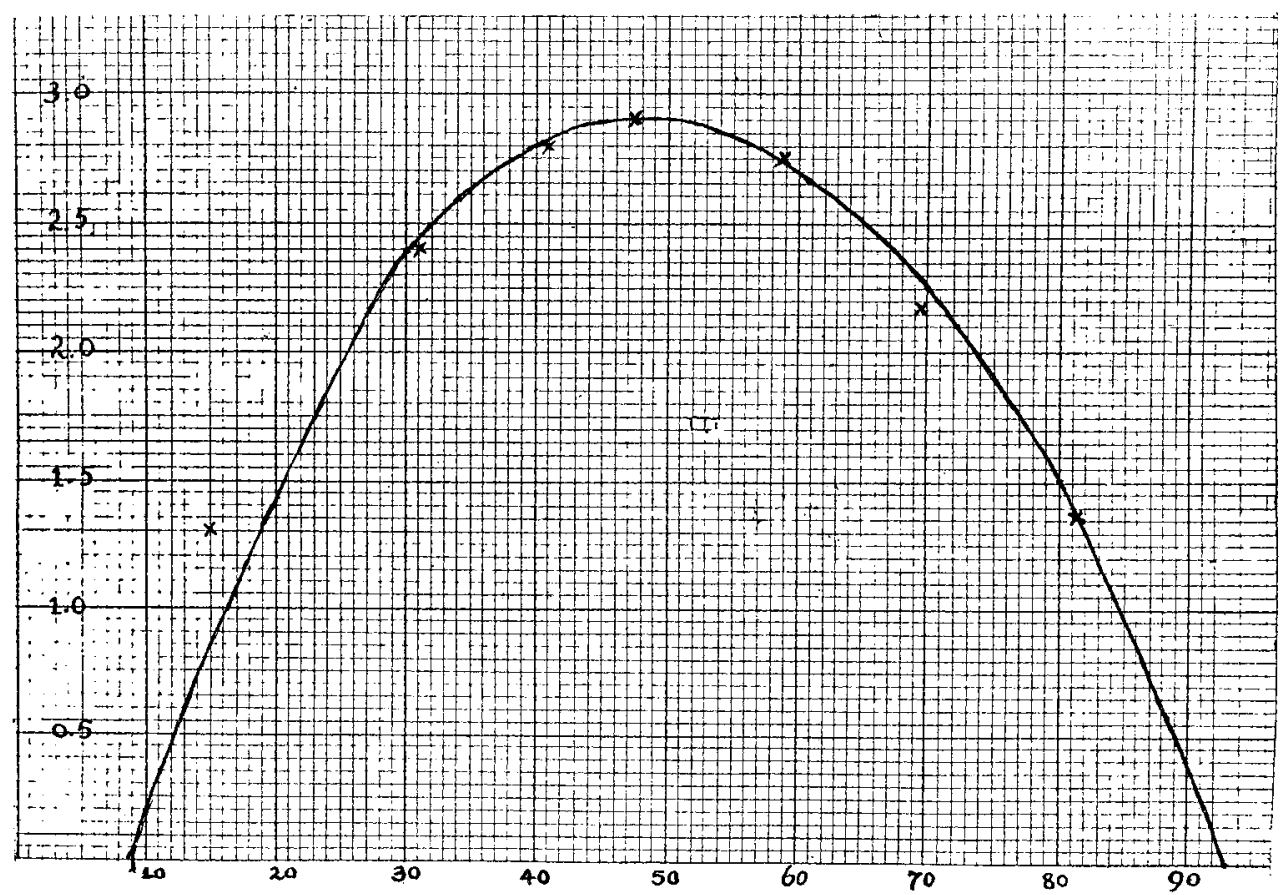

Fig. I.-Graph showing the shrinkage in volume when water is added to 93 percent alcohol. Figures on the abscissa indicate expected percent of alcohol; figures on the ordinate indicate percent of shrinkage in the volume of the mixture. Curved line is drawn from calculations based on Pharmacopoeial tables (see Table 2); crosses represent experimental averages (from Table I).

For reasons of convenience, I have used in these experiments an alcohol con taining 93 percent by volume. I have found that our laboratory alcohol, supposedly 95 percent, showed this latter concentration, when tested by the hydrometer, only at a temperature of approximately $25^{\circ} \mathrm{C}$. At the official temperature of $15.56^{\circ}$, it represented about 93.5 percent of alcohol. In order to avoid the complications of dealing with too many fractions, I added water to bring the percentage down to correspond with 93 percent at $15.56^{\circ}$, measured by the Tralles hydrometer.

The method of experimentation employed was as follows: A carefully mea- 
sured amount of alcohol, varying from ro to 25 mils, was placed in a burette graduated in tenths of a mil. To this was added a measured volume of distilled water, say 5 mils. The burette was then tightly stoppered and reversed several times to assure a thorough commingling of the alcohol and water, allowed to stand for a few minutes, in order that the temperature of the mixture might return to its norm, and the volume of the mixture read. The difference between the volume read and the sum of the amounts of alcohol and water taken, represents the amount of shrinkage which has taken place; by a simple arithmetical calculation was determined the percentage of shrinkage. To this mixture were then made further additions of water, usually in 5 mil portions, with similar readings and calculations after each addition. In this way was obtained a series of figures showing the diminution of volume by adding water to varying strengths of alcohol.

The quantities employed being so small, it was not surprising that there was quite a little variation in the individual results. For example, three observations with mixtures of water and alcohol in the proportions which should have yielded an alcohol of 40.7 percent (in all cases, unless otherwise stated, the percentage of alcohol refers to volume percent); the shrinkage in one was 2.57 percent, in another, 2.29 percent, and in the third 2.70 percent. While there were considerable individual variations, by repeated experiments average figures were obtained which were consistent with each other and also with a theoretical shrinkage, figured, in a manner I shall describe, from the tables in the Pharmacopoeia. The amount of shrinkage is given both in a table and in a curve, made by plotting the various observations. I may say here, that in a general way the shrinkage was greatest at a little over 50 percent, amounting to about 2.9 per cent, and diminished at about the same rate when either the quantity of water or alcohol was lessened. The lowest percentage of alcohol tested was 8.48 percent, which gave a shrinkage of 0.63 ; and the highest 83.13 percent, with a shrinkage of 1.25 percent (see Table $\mathbf{r}$ ).

Table 1. Showing Shrinkage Found Experimentally with Alcohol-Water Mixtures.

\begin{tabular}{|c|c|c|c|c|c|}
\hline $\begin{array}{l}\text { Expected Percent } \\
\text { Alcohol. }\end{array}$ & $\begin{array}{l}\text { Shrinkage. } \\
\text { Found. }\end{array}$ & Averages. & $\begin{array}{c}\text { Expected Percent } \\
\text { Alcohol. }\end{array}$ & $\begin{array}{c}\text { Shrinkage. } \\
\text { Found. }\end{array}$ & Averages. \\
\hline \multirow[t]{2}{*}{8.48} & $0.63 \%$ & & $50.8 \mathrm{I}$ & $2.67 \%$ & \\
\hline & & & 53.78 & 2.78 & \\
\hline 14.43 & I .72 & & 53.92 & 2.98 & \\
\hline $15 \cdot 57$ & I . 07 & & $5^{2} \cdot 50$ & $\ldots$ & 2.810 \\
\hline 15.00 & $\ldots$ & I. 395 & 55.42 & 2.90 & \\
\hline 24.17 & 2.29 & & 59.43 & 2.83 & \\
\hline 31.67 & 2.00 & & $58.8 \mathrm{I}$ & 2.86 & \\
\hline 31.67 & 2.33 & & $6 \mathrm{I} \cdot 58$ & $2.4 \mathrm{I}$ & \\
\hline 32.17 & 2.93 & & $58.8 \mathrm{r}$ & $\ldots$ & 2.750 \\
\hline 31.86 & $\ldots$ & 2.420 & 66.50 & 2.20 & \\
\hline 38.54 & 3.04 & & 67.85 & 2.43 & \\
\hline $40.7 \mathrm{I}$ & 2.29 & & $\ldots \ldots$ & $\ldots$ & \\
\hline $40.7 \mathrm{I}$ & 2.57 & & 73.88 & I .89 & \\
\hline 40.75 & 2.70 & & $69.4 I$ & $\ldots$ & 2.750 \\
\hline 43.77 & $3 \cdot 3 I$ & & $\ldots$. & $\ldots$ & \\
\hline 40.90 & $\ldots$ & 2.802 & $79 \cdot 16$ & I. 50 & \\
\hline $47 \cdot 50$ & 2.80 & & $\ldots \ldots$ & & \\
\hline 47.50 & 2.97 & & $83 \cdot 13$ & I . 25 & \\
\hline 47.50 & $\ldots$ & 2.885 & $81 \cdot 14$ & $\ldots$ & I. 375 \\
\hline
\end{tabular}


As just mentioned, it is possible to figure the proportion of shrinkage, when mixtures of absolute alcohol and water are used, from the alcoholometric tables in the Pharmacopoeia. This was done on the following basis: suppose, for example, it is desired to know the amount of shrinkage when 60 volumes of absolute alcohol are mixed with 40 volumes of water. First, obtain the weight percent of the alcohol in this mixture, by multiplying 60 by 0.79365 (the specific gravity of absolute alcohol); to this is added 40 (the quantity of water used) and divide this sum into the weight of alcohol employed. The weight percent obtained in this manner is 54.348. By reference to the Pharmacopoeial tables, it is found that an alcohol containing this weight percentage is equivalent to a volume percent of 62.193 . Evidently, there has been a diminution in the volume of the mixture; the volume of the mixture may be determined by dividing 60 (the expected percentage) by 62. 193, the found percentage. The result of this division equals 96.475 . Subtract this from roo, and we get the figures 3.525 , representing the percentage of shrinkage which takes place when 60 volumes of absolute alcohol are mixed with 40 of water. Similar calculations were made for ten different proportions of alcohol and water, enough to allow the construction of a curve representing the shrinkage of mixtures of alcohol and water. (See Table 2.) It was found that, with absolute alcohol the shrinkage was greatest when 54 parts of alcohol were mixed with 46 parts of water, being equal to 3.612 percent of the expected volume.

Table 2. Showing Shrinkage in Alcohol,-Water Mixtures Figured from Alcoholo-

Expected
Percent
Alcohol.
10
20
30
40
50
54
60
70
80
93
metric Table of U. S. Pharmacopoeia.

$\begin{array}{lcc}\begin{array}{c}\text { Found } \\ \text { Percent } \\ \text { Alcohol. }\end{array} & \begin{array}{c}\text { Shrinkage } \\ \text { with 100\% } \\ \text { Alcohol. }\end{array} & \begin{array}{c}\text { Shrinkage } \\ \text { with } 93 \% \% \\ \text { Alcohol. }\end{array} \\ 10.07 & 0.715 & 0.575 \\ 20.345 & 1.696 & 1.416 \\ 30.833 & 2.699 & 2.380 \\ 41.388 & 3.353 & 2.794 \\ 51.866 & 3.595 & 2.897 \\ 56.017 & 3.612 & 2.858 \\ 62.193 & 3.526 & 2.688 \\ 72.320 & 3.209 & 2.236 \\ 82.160 & 2.629 & 1.512 \\ & 1.299 & 0.00\end{array}$

It is obvious that since a considerable diminution in volume takes place when 7 parts of water are added to 93 of alcohol (in making a 93 percent alcohol), the amount of shrinkage which would take place when 93 percent of alcohol is mixed with the water, would be less than that indicated in the accompanying table. To determine this difference, I first found the shrinkage in reducing roo to 93 percent alcohol; this is I 299 percent. This is then multiplied by the number of parts of alcohol taken-for instance, with the example given above, by 60 -and since it would take obviously more than 60 parts of 93 alcohol to make 60 volume percent, the result of this multiplication was divided by 0.93 . This factor, representing the difference due to shrinkage in 93 percent alcohol, is then to be subtracted from the shrinkage found in roo per cent alcohol. When this is done, as may be seen by reference to the tables $I$ and 2 , the result is very close to the average shrinkage obtained in my observations, varying from them only in the second decimal place. I have constructed a curve showing the theoretical shrinkage 
(figured from the U.S. P. tabjes) on which are marked the averages (from Table I) which I obtained by actual experiment. Table 3 gives the shrinkage and true volume percent of alcohol when 93 percent alcohol is mixed with water in the proportions which should form various strengths of alcohol.

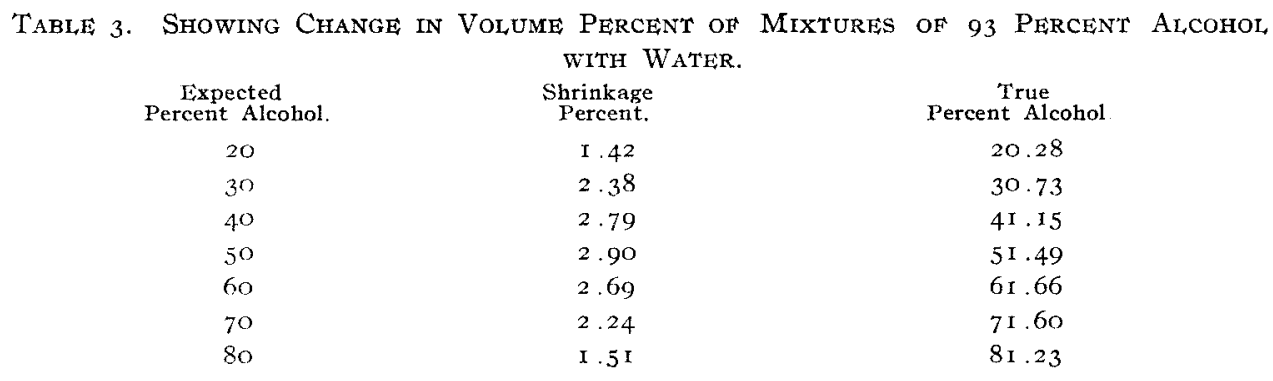

\section{A NOTE ON A VERY OLD SPECIMEN OF PEPSIN.}

BX I. E. WARREN.

An occasion recently arose to examine some rather old pharmaceutical preparations which were claimed to contain pepsin. Since the specimens were of unknown age (but known to be at least about 9 years old) the question arose as to the proper method to be used for making the test for proteolytic power. Since it was not the object of these tests to determine whether the preparations contained pepsin conforming to the present U. S. P. standards, and as the laboratory constant temperature bath was in use for other experiments at $40^{\circ} \mathrm{C}$. and was to be so employed for a long period, it was decided to use this temperature according to the method prescribed by the U. S. Pharmacopoeia of 1890 for the valuation of pepsin. In brief, the method consists in digesting ten grammes of moist egg albumen for six hours at a temperature of from 38 to $40^{\circ} \mathrm{C}$. with Ioo Cc. of 0.2 percent hydrochloric acid which contains $0.0035 \mathrm{Gm}$. of pepsin.

As some of the preparations to be tested (tablets) had been in the laboratory for a number of years the question of the stability of pepsin had to be considered. It chanced that a very old specimen of pepsin and. another which had been received ten years before were in stock. It seemed worth while to compare the proteolytic activity of the two old specimens with a specimen of pepsin of recent purchase, using the assay method outlined above as employed on the other pepsin preparations.

The history of the old specimen was not positively established but it is believed to have been prepared by Mr. F. S. Hereth. The label bore the statement that it had been prepared during the months of October and November, I880. Consequently at the time of this test (July), its age was probably nearly thirtynine years. Unfortunately its initial proteolytic strength was not known, but since the methods for preparing pepsin were not so refined four decades ago as now, it is probable that the specimen was not of I to 3000 value as is now required by the standards of the U. S. Pharmacopoeia. So far as the evidence could be ascertained the specimen had been stored in a small, cork-stoppered, green-glass bottle at the temperature of the laboratory since the date of manufacture and the 